DOI: 10.22201/cimsur.18704115e.2020.v15.502

\title{
La 72, Hogar-refugio para personas migrantes:
}

\section{la sociedad civil organizada en la atención de la agenda de los transmigrantes en la frontera México-Guatemala.}

\section{La 72, A Shelter for Migrants: \\ Organized Civil Society and the Transmigrants Agenda along the Border between \\ Mexico and Guatemala}

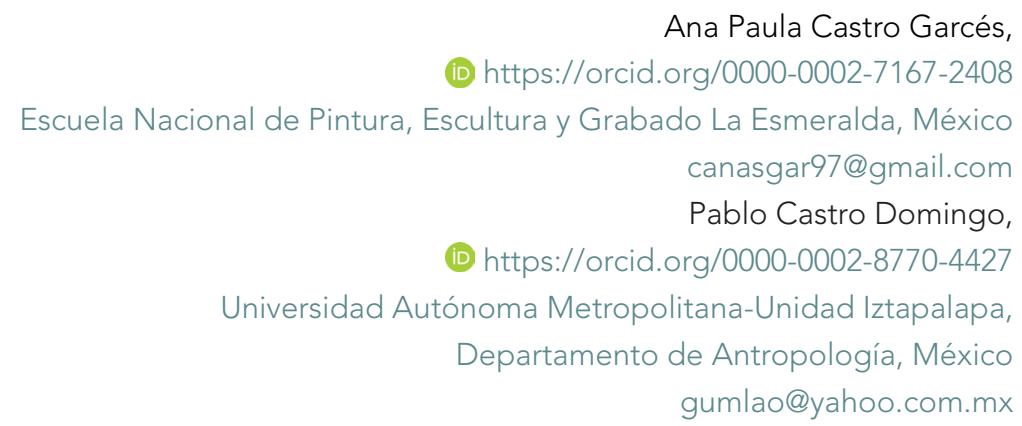

Resumen:

En este artículo analizaremos a La 72, Hogar-refugio para personas migrantes, en el municipio de Tenosique, Tabasco, frontera con Guatemala, para explicar cómo las organizaciones de la sociedad civil están incidiendo en la atención a los migrantes centroamericanos, hombres, mujeres, niños y miembros de la comunidad LGBTTTI como las mujeres trans, en el marco de un contexto internacional complejo donde los Estados Unidos de América han influido para que México construya un cerco en su frontera sur con la presencia de la Guardia Nacional y con políticas del Instituto Nacional de Migración que suspenden el ingreso de asociaciones religiosas y organizaciones de la sociedad civil en las estaciones migratorias y estancias provisionales. Palabras clave: Frontera, transmigrantes, sociedad civil, reforma del Estado.

Abstract:

This paper analyzes a shelter for migrants named La 72 Hogar-Refugio para personas migrantes (Number 72, A Shelter for Migrants), located in the municipality of Tenosique, Tabasco State, Mexico, on the border with Guatemala. It explains how civil society associations impact care for Central American migrants, women, men, chil- 
dren and members of the LGBTTTI community. This work takes place within the framework of a complex international context in which the United States of America has influenced Mexico to create a barrier along its southern border with the presence of the Mexican National Guard and policies implemented by the Mexican National Institute of Migration banning access by religious associations and civil society organizations to migration stations and temporary shelters.

Keywords: Border, transmigrants, civil society, non-profit organization, State reform.

Recibido:20/04/2020

Aceptado:10/07/2020

Publicado: $17 / 11 / 2020$

\section{Introducción}

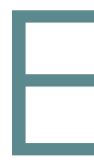

n las últimas décadas, México ha experimentado una notable transformación política como consecuencia de un repunte en la participación de la sociedad y de nuevos diseños institucionales del Estado; en 1990, por ejemplo, se alcanzaron notables logros en términos político-electorales con la consolidación del Instituto Federal Electoral como una institución fundamental para garantizar la transparencia de los procesos electorales. Asimismo, México adoptó una serie de acuerdos internacionales que incidieron en la reforma del Estado que impactó en la estructuración de procesos de gobernanza horizontales. No obstante, «el proceso de cambio no ha sido homogéneo a lo largo y ancho del país, porque hay regiones que han empezado a transitar por un proceso democratizador» (Castro, 2013:59), pero hay otras que aún reproducen prácticas clientelares, corporativas y patrimonialistas.

En las líneas siguientes se analizará a La 72, Hogar-refugio para personas migrantes (La 72), ubicado en el municipio de Tenosique, en el estado de Tabasco, frontera con Guatemala, para explicar la incidencia que tienen algunas organizaciones de la sociedad civil en la atención a los migrantes centroamericanos. Esto, en el marco de una coyuntura internacional problemática donde las presiones políticas del presidente estadounidense Donald Trump han influido para que el presidente mexicano, Andrés Manuel López Obrador, construya una política agresiva frente a los migrantes que intentan transitar por México. 
Esto representa un obstáculo para el ejercicio de los derechos humanos, pero sobre todo una afrenta al derecho a recibir asistencia, acompañamiento integral y representación legal de la población migrante con necesidades de protección internacional en detención migratoria.

Para esta investigación ${ }^{1}$ realizamos ocho estancias de trabajo de campo de un mes a mes y medio en La 72 entre 2015 y 2019, lo que nos permitió construir una etnografía sobre la casa albergue, sus tareas y su vinculación con diversos actores de la municipalidad de Tenosique y del estado de Tabasco. En la primera parte de este artículo hacemos un breve recorrido por algunos de los paradigmas más influyentes sobre resistencia, porque con esta noción podemos entender los procesos de empoderamiento por los que pasan las organizaciones de la sociedad civil; en la segunda parte se analizan los efectos de la reforma del Estado y su incidencia en la emergencia de estas en México; en la tercera, hacemos un recorrido general por los andamiajes institucionales de las organizaciones de la sociedad civil; en la cuarta analizaremos a La 72 Hogar-refugio para personas migrantes como un caso paradigmático de organizaciones que están atendiendo la agenda migratoria en la frontera entre México y Guatemala. Finalmente, presentamos las conclusiones que se desprenden de las prácticas implementadas por La 72 en la defensa de los derechos humanos de los transmigrantes centroamericanos.

\section{Ideas teóricas}

Para poder explicar la incidencia de La 72 en la atención y apoyo a los transmigrantes centroamericanos, consideramos que la noción de resistencia puede ser útil para entender cómo las tareas implementadas en la casa albergue operan como repertorios de acción frente a las presiones de un actor tan poderoso como lo es el Estado mexicano. Más aún, con los procesos de resistencia, actores como fray Tomás González -director del hogar-refugio- se empoderan y ejercen poder en los procesos de negociación con funcionarios del Instituto Nacional de Migración (INM) o con el Presidente Municipal de Tenosique, Francisco Ramón Abreu Vela (del Partido Revolucionario Institucional). La resistencia es una categoría analítica que alude al ejercicio del poder, es decir, a la capacidad que tiene un actor para influir en la voluntad de un segundo actor, con

\footnotetext{
1 Este texto es el inicio de una investigación antropológica que queremos emprender en el marco de la frontera sur.
} 
base en el control de recursos significativos (Adams, 1978); pero lo significativo de este poder construido desde abajo es que es ejercido por actores que habitualmente no tienen la capacidad de influir en actores o sectores poderosos. Una interesante perspectiva sobre la resistencia ha sido desarrollada por James Scott, quien analizó la resistencia campesina en Malasia y planteó que las formas de lucha o movilizaciones de masas no se perciben como opciones viables simplemente porque resultan demasiado peligrosas dado el poder represivo de las clases hegemónicas y de los estados que las respaldan. Scott postula que los powerless no aceptan de forma pasiva la creciente diferenciación social vinculada a la comercialización y cambio tecnológico que acentúan su pobreza e inseguridad; para él las pequeñas resistencias cotidianas son los disparadores de los posibles cuestionamientos sobre el poder (Scott, 1985). Con gran lucidez Scott:

ha mostrado cómo las estructuras de poder más sólidas son incapaces de lograr una absoluta dominación sobre los sectores que concentran menos poder. En la sumisión de los sectores subalternos se esconde su resistencia, esto es, el poder de las formas sociales que se manifiesta en las relaciones de las reglas de etiqueta y cortesía, muchas veces exige que algunos actores sacrifiquen su sinceridad para tener relaciones apacibles con todos aquellos con quienes mantienen una relación asimétrica. Los subordinados, ya por prudencia, ya por miedo, o por el hecho de buscar favores, le dan a su comportamiento una forma adecuada a las expectativas de los poderosos (Castro y Rodríguez, 2009:118).

Scott señala que en la medida en la que el ejercicio del poder sea más arbitrario, los subordinados implementarán prácticas sociales más estereotipadas y ritualizadas. En ese sentido, sugiere que debemos estudiar los discursos ocultos, pues de lo contrario solo entenderemos una parte del ejercicio del poder, pero nada sobre los mecanismos de resistencia (Scott, 2000).

Con la noción de resistencia podemos:

entender la vitalidad de movimientos contemporáneos en el mundo pues es un proceso asociado a subculturas subalternas que comparten códigos colectivos que poseen el potencial de transformar radicalmente las estructuras, las categorías y la lógica de la dominación. Ahora bien, como ha señalado William Roseberry (1994) la resistencia no puede ser explicada al margen de la dominación, porque incluso sus formas y sus lenguajes deben adoptar sus códigos para poder ser escuchados. De hecho, las estructuras de dominación limitan los modos en que los subalternos pueden resistir a su condición (Castro y Rodríguez, 2009:118). 
Estos planteamientos han atraído a los antropólogos que pretenden explicar los patrones culturales de la subordinación y dominación. Incluso las exigencias teatrales que generalmente se imponen en las situaciones de dominación producen un discurso social que corresponde a la apariencia que el grupo dominante quiere dar. No obstante, como plantea Sherry Ortner (1995), se debe mantener una alerta epistemológica permanente frente a las tendencias a idealizar a los grupos subalternos. Ella señala que estos no son entidades homogéneas, sino que muestran una gran diversidad interna e incluso presentan importantes rupturas. Al igual que en otros grupos sociales, en su interior algunos sectores dominan a otros. Como consecuencia, los subalternos no se manifiestan como un grupo unitario en términos identitarios ni, mucho menos, con una conciencia o ideología uniforme.

Con base en lo mencionado, tenemos un instrumento analítico sólido para entender cómo las organizaciones de la sociedad civil implementan estrategias para atender la agenda migrante incluso frente a las presiones del Estado.

\section{Reforma del Estado y emergencia de las organizaciones de la sociedad civil en México}

Como ha señalado Luis Aguilar (Hernández, 2018), a inicios de la década de los ochenta en el siglo pasado, México resintió el efecto de la crisis hacendaria que estimuló una serie de políticas de ajuste, un cambio de modelo de desarrollo y un movimiento de transición hacia la democracia. Estos factores influyeron en un debilitamiento del centralismo y en una elaboración de paradigmas en favor de la descentralización. Pero en ese contexto, como diría Assies (2003), de manera concurrente se presentó una tendencia mundial hacia la flexibilización con la intencionalidad de mejorar la coordinación y la eficacia con la lógica de atender las necesidades más apremiantes.

En este proceso se puede delinear de manera nítida que en los sistemas políticos autoritarios las acciones de gobierno son uniformes, universales, construidas por elites y con una exigua participación ciudadana. En los sistemas autoritarios en donde la concentración del poder y el principio de autoridad en todos los niveles de gobierno son primordiales, la ciudadanía se ve confinada y desactivada por lo que su incidencia en la construcción de la agenda pública resulta muy acotada (Flores, 2012:18). Este fue un rasgo característico de México hasta antes de la década de los ochenta, de hecho, los actores operaban en 
redes clientelares, corporativas, con posiciones sumisas frente al poder y reproducían esquemas de ciudadanías restringidas. Por otro lado, como señala Assies (2003), la crisis fiscal de los Estados latinoamericanos encaminó a organismos multilaterales como el Fondo Monetario Internacional a condicionar sus créditos a una reestructuración de los sectores estatales y de la provisión de servicios, dando paso a la privatización, desconcentración y descentralización, con esta última se buscaba alcanzar políticas de austeridad y disipar las tensiones distributivas exacerbadas por la crisis financiera e impedir su canalización hacia el Estado central. Ahora bien, Assies (2003) plantea que mientras las primeras reformas del Estado que operaron en la década de los ochenta e inicios de los años noventa se encauzaron a la disminución del tamaño del Estado, siguiendo las líneas del Consenso de Washington, ${ }^{2}$ la segunda generación de reformas del Estado se encaminó a la administración pública, la justicia, la legislación laboral y a una nueva legislación antimonopolio en mercados de capital. La reforma del Estado implicó no solo una respuesta a la crisis financiera y a la legitimidad, sino también un severo cuestionamiento a los andamiajes institucionales del Estado-nación.

La descentralización surgió como una respuesta a las exigencias de los procesos de democratización y como parte de la estrategia para el adelgazamiento del Estado. La desregulación de la economía y el proceso de globalización proveen nuevos elementos contextuales. Los procesos de reforma del Estado y las respuestas de los actores sociales locales están vinculados, por un lado, a las transformaciones de los sistemas productivos y los procesos de toma de decisiones $y$, por otro, a los procesos de cambio cultural y a la redefinición de las identidades socioculturales suscitados por el proceso de globalización (Assies, 2003:20).

Como ha señalado Assies (2003), en América Latina la reforma condujo a un adelgazamiento del Estado, a una transición a gobiernos civiles y a una economía de libre mercado. Este acotamiento de las funciones del Estado transformó los espacios públicos en privados y delegó sus responsabilidades históricas a las organizaciones de la sociedad civil.

\footnotetext{
2 El Consenso de Washington buscó alcanzar la estabilidad macroeconómica y desmontar el Estado desarrollista, liberalización de los regímenes comerciales y de inversión, desregulación de los mercados y privatización de las empresas paraestatales (Assies, 2003).
} 


\section{Soportes institucionales de las organizaciones de la sociedad civil}

Como punto de partida podemos decir que la sociedad civil está integrada por asociaciones, organizaciones no gubernamentales, instituciones de asistencia social y grupos voluntarios que participan en la resolución de problemas que afectan a los ciudadanos e intentan posicionarlos como parte de la agenda pública. Estas organizaciones buscan influir en ese ámbito institucional para alcanzar la solución de problemas, no tienen fines de lucro, sino que sus incentivos se dirigen hacia la atención de problemas públicos de terceros. En el pasado, las organizaciones de la sociedad civil no intervenían directamente en el proceso de toma de decisiones, pero en el presente buscan incidir en la agenda pública con temas muy variados como la defensa del ambiente, la prevención del $\mathrm{VIH}$, la atención a madres solteras, a niños en situación de calle, la atención a adultos mayores, el apoyo a personas con discapacidad, la defensa de derechos humanos, e incluso la transparencia y rendición de cuentas, entre otros. Como puede verse, el abanico de posibilidades temáticas de la agenda de las organizaciones de la sociedad civil es muy variado y plural. En particular, con las caravanas de migrantes provenientes de Honduras, El Salvador y Guatemala, el tema migratorio ha sido retomado por grupos defensores de derechos humanos, organizaciones de la sociedad civil, organizaciones confesionales, organismos multilaterales como la Oficina del Alto Comisionado de las Naciones Unidas para los Refugiados (ACNUR), Médicos Sin Fronteras, entre otros. Con esto, las organizaciones de la sociedad civil han desempeñado un papel central como actores del foro público, de tal suerte que ya no solo son los políticos quienes toman decisiones y diseñan directrices políticas, sino que los propios ciudadanos inciden con su pericia para asegurar mejores tratos y garantías en los derechos humanos de los migrantes.

En este sentido, hay que ser precavidos con idealizar a las organizaciones de la sociedad civil, porque los académicos más progresistas y mejor intencionados las consideran como actores que le han ganado espacios al Estado y lo han acotado en sus funciones. Pero existe otra posición que plantea que fue el Estado con su adelgazamiento quien obligó a las organizaciones de la sociedad civil a atender tareas y funciones que desatendió. Por esta razón, nos parece pertinente recuperar la discusión introducida por Jean y John Comaroff (1999) sobre la sociedad civil en África, quienes argumentan que al limitarse a la acción política que se opone al Estado de una forma explícita y organizada, descartan 
las formas de participación que han sido relevantes en la historia de África como los sindicatos, las cruzadas islámicas reformistas, las iglesias activistas, las asociaciones mercantiles y las alianzas populistas pro democracia.

En la discusión sobre organizaciones de la sociedad civil, Cohen y Arato (2002) plantean que estos actores se encuentran en la búsqueda de prácticas autonómicas con respecto a las esferas del mercado y del Estado. Ahora, ciertamente las organizaciones de la sociedad civil no pueden estar al margen de la economía y de la política, puesto que requieren recursos para garantizar su operación y su pervivencia, y para realizar, en específico, el trabajo para lo que fueron creadas, esto es, la defensa de derechos humanos, la atención a niños en situación de calle, la limpieza de las cuencas hidrológicas, el combate a la violencia con arte experimental, el apoyo a la salud reproductiva y la equidad de género, entre otros. Sin embargo, en muchos casos el fondeo es la actividad que les demanda un mayor esfuerzo y tiempo, y terminan dedicándole pocas horas a las actividades sustantivas que les dieron origen. Por otro lado, hoy día es muy común encontrar organizaciones de la sociedad civil con una clara intencionalidad de incidencia en las decisiones de actores políticos y esferas de poder.

Sobre la agenda migratoria existen muchas organizaciones de la sociedad civil en México, pero con una orientación de casa-albergue, confesionales y similares a La 72, Hogar-refugio para personas migrantes, encontramos muy pocas a lo largo y ancho del país. Es decir, plenamente reconocidas bajo esta denominación tenemos a las siguientes:

Albergue Decanal Guadalupano para migrantes, Albergue "Manos extendidas a los Necesitados" A. C., Albergue "Todo por ellos" A. C., Albergue para migrantes "La Sagrada familia", Albergue para migrantes "San Juan Bosco" IAP, Albergue para migrantes "Casa Tochan", Albergue para migrantes"Hermanos del camino", Albergue para migrantes "Jesús el buen pastor", Casa del Migrante de la Diócesis de Coatzacoalcos, Casa del Migrante Ruchagalu, Casa del Infante repatriado "Camino a casa", Casa del Migrante Betania Diócesis de Mexicali, Casa de la Caridad-Hogar del Migrante "Monseñor Luis Morales Reyes", Casa de la Mujer Migrante, Casa de Oración del Migrante A. C., Casa de Paso de Asistencia al Migrante "San Francisco de Asís", Casa del Migrante "El Buen Samaritano", Casa del Migrante Casanicolás, Casa del Migrante de Mapastepec, Casa del Migrante de Saltillo [Frontera con Justicia, A. C.], Casa del Migrante en Juárez A. C., Casa del Migrante "Hogar de la Misericordia", Casa del Migrante "San Carlos Borromeo", Casa del Migrante "San Rafael", Casa del Migrante Scalabrini, 
A. C.-Albergue Belén, Casa el Caminante Jtatic Samuel Ruiz García Diócesis de San Cristóbal, Centro Madre Assunta, Centro Pastoral Maná de Mexicali, Centro Comunitario de Atención al Migrante y Necesitado, Centro Comunitario de Ayuda al Migrante, Centro de Atención al Migrante Exodus, Centro de Ayuda Humanitaria Chahuites A. C., Comedor Padre González Ministerios de Amor, Comedor "El Pescador", Comedor Iniciativa Kino para la Frontera, Desayunador Salesiano "Padre Chava", Ejército de Salvación A. C., FM4 Paso Libre, La Casa del Migrante Irapuato San Juan de Dios A. C., Ministerios Cristianos "La Roca" y Parroquia San José Obrero, Comedor El buen Samaritano Pastoral de Migrantes de la Diócesis de Querétaro (CNDH, 2018:215-216).

Cabe mencionar que muchas de estas organizaciones de la sociedad civil son conservadoras, poco incluyentes con respecto a ideas políticas, rígidas frente a otras confesiones y abiertamente intolerantes frente a la diversidad y pluralidad de identidades de género. En particular con respecto a la homosexualidad, muchas de las organizaciones antes citadas recuperan las reflexiones de la jerarquía de la Iglesia católica, es decir, que la complementariedad de hombre y mujer es inherente al diseño creativo de Dios. Asimismo, algunas consideran que los actos homosexuales no pueden realizar los fines naturales de la sexualidad humana, porque dado que no reconocen el matrimonio entre personas del mismo sexo, luego entonces plantean que todo acto sexual que tiene lugar fuera del lazo del matrimonio no cumple los fines propios de la sexualidad humana: la procreación y la unión. Así, para la jerarquía de la Iglesia católica la homosexualidad es un acto desordenado en cuanto a que no está de acuerdo con este doble fin y, por tanto, es moralmente equivocado. Por esta razón resulta muy sugerente examinar a La 72 por tratarse de una organización de la sociedad civil confesional, abierta a las ideas, tolerante con las creencias, incluyente con la diversidad y con una postura plural y ecuménica.

\section{La 72, Hogar-refugio para personas migrantes}

En los últimos años las migraciones internacionales:

han llamado la atención de académicos, políticos y organizaciones de la sociedad civil por las implicaciones que reviste este proceso en términos de relaciones internacionales, de política exterior, de política económica y de los movimientos locales. Los procesos migratorios se han convertido en los ejes de la agenda de 
muchos países en el mundo, en gran medida porque los flujos de personas a través de las fronteras internacionales han estimulado importantes cambios en su economía, en su política, en su religión y hasta en su propia cultura (Castro, 2015: 624).

Con base en estimaciones de la Organización Internacional para las Migraciones (OIM), Rodolfo Casillas y Rodolfo Córdova señalan que,

son 400 mil personas las que engrosan el volumen total de migrantes indocumentados en México al año (OIM, 2015). De ese posible volumen, la migración continua por México de personas del norte centroamericano, que data de los años 90 del siglo XX, es la que más engrosa el volumen total de extranjeros indocumentados detenidos por el Instituto Nacional de Migración (INM), tal y como se observa en el cuadro 1 [...] más del 90\% de ellos proceden de esos países de Centroamérica (Casillas y Córdova, 2018:5).

No obstante, las prácticas migratorias, también, conllevan riesgos considerables porque los transmigrantes son presa de grupos de la delincuencia organizada que los extorsionan, trafican con ellos y en el peor de los escenarios, los desaparecen. Al respecto, Casillas y Córdova plantean que los delitos contra migrantes internacionales han sido constantes y la mayor paradoja es que mientras aumentan los controles migratorios más se expanden los abusos y delitos.

Ejemplo de ello es la información recopilada por la Red de Documentación de las Organizaciones Defensoras de Migrantes, que señala que, en 2015, de las 1,768 personas que sufrieron algún delito, en $42 \%$ de los casos fue por parte de alguna autoridad -en comparación con 20\% en 2014- (Redodem, 2016); ese porcentaje es prácticamente igual que los delitos cometidos por el crimen organizado (46\%). Según un informe de Fundar, WOLA y otras organizaciones y albergues hay tres elementos de preocupación:

1. El secuestro, la desaparición forzada y otros tipos de privación de la libertad de migrantes se mantienen en niveles altos.

2. Entre 2014 y 2016 han aumentado 575\% los migrantes que regularizaron su situación migratoria por haber sido víctimas o testigos de delitos graves.

3. La impunidad se mantiene en niveles alarmantes, como a nivel nacional, ya que en el periodo 2014-2016 de un total de 5,824 delitos en contra de migrantes en Chiapas, Oaxaca, Tabasco, Sonora, Coahuila y del fuero federal solo existen 49 sentencias (1\%) (Casillas y Córdova, 2018:17). 
Habitualmente las redes sociales les permiten a los migrantes organizarse de tal forma que puedan disminuir el riesgo en su tránsito. Estas se reactivan por medio del parentesco, la amistad y las relaciones de paisanaje. Con el parentesco como parte fundamental de la red social se estrechan los vínculos entre toda la estructura familiar, donde padres e hijos se fusionan para enfrentar el ambiente extraño de la llegada. Los hermanos, sobrinos y primos juegan, también, un papel fundamental en esta red familiar, porque su participación en fiestas como bodas, quince años, bautizos o confirmaciones, permite estrechar lazos de comunicación y ayuda. Asimismo, la amistad es otra relación que posibilita la aparición de una red, ya que la afinidad y las experiencias compartidas permiten construir espacios de sociabilidad. Por ejemplo, situaciones como compartir un lugar de residencia, dar o recibir información sobre algún empleo y socializar, generan que las relaciones interpersonales dentro del sistema migratorio se extiendan y amplíen. Por último, la identidad con paisanos dentro de un territorio migratorio obliga casi instantáneamente a generar lazos de simpatía e integración, ya que se comparten recuerdos y vivencias afines como el futbol, la fiesta del pueblo, la comida y otros acontecimientos que le dan cohesión a la red social. Las redes sociales son un vehículo muy eficiente para permitir grandes movimientos de personas porque reducen los costos del viaje al proporcionar información sobre rutas de arribo y posibilitan la inserción en los nuevos mercados laborales. Sin embargo, estas redes quedan interferidas por la violencia, el abuso de autoridad y la presencia de grupos delincuenciales (Castro, 2015:240).

En años recientes la migración de centroamericanos hacia los Estados Unidos de América se ha incrementado de manera sustancial principalmente por las contracciones de la economía, el deprimido mercado laboral, la falta de desarrollo, los conflictos políticos, los efectos devastadores de los fenómenos naturales y la violencia. Esto, por ejemplo, condicionó la salida en 2015 de las primeras caravanas de transmigrantes de Honduras, El Salvador y Guatemala, que partieron justo desde La 72 en Tenosique transitando por todo México hasta llegar a los Estados Unidos de América.

En una situación de alta vulnerabilidad se encuentran los transmigrantes que ingresan a México por la frontera sur, pero en el desamparo total estos actores han encontrado el respaldo y el apoyo solidario de organizaciones de la sociedad civil como Las Patronas, en el municipio de Amatlán de los Reyes, Veracruz, que a lo largo de las vías del tren regalan comida y agua; o de casas-al- 
bergue que dan refugio, comida, vestido y asesoría legal a personas en tránsito. Asimismo, con el apoyo de estas organizaciones los migrantes se han constituido como actores que se han empoderado en términos de la defensa de sus derechos y han logrado resistir a los duros embates que imponen los contextos de frontera de nuestro país.

A continuación analizaremos las estrategias de resistencia implementadas tanto por La 72, Hogar-refugio para personas migrantes, en Tenosique, una organización de la sociedad civil de la orden de los franciscanos, como por los propios transmigrantes. La orden de los franciscanos es una fraternidad que tiene como misión la profesión de la obediencia, la pobreza y la castidad. Dentro de su agenda está la erradicación de las pobrezas en el mundo hacia el año 2030, por esta razón, en su trabajo pastoral los franciscanos han creado organizaciones de la sociedad civil que tienen como foco de atención la defensa de los derechos humanos, la supresión de la pobreza, la conservación de la diversidad ambiental, disipación de la violencia y la desaparición del hambre. Esto explica por qué participan cotidianamente en la erradicación de los problemas que atañen a las sociedades contemporáneas.

La municipalidad de Tenosique, situada en la frontera sur, ha estado constreñida por políticas enmarcadas en la relación de México con los Estados Unidos. Como señala Gutiérrez (2017), un antecedente fundamental del papel de México como un filtro de la migración hacia la Unión Americana, fue la firma, en 2008, del Plan Mérida entre los otrora presidentes Felipe Calderón y George Bush, y que continuaron los gobiernos de Enrique Peña Nieto y Barack Obama. El Plan Mérida buscaba mejorar la infraestructura y tecnología para modernizar la seguridad fronteriza en los cruces terrestres del norte y del sur (Gutiérrez, 2017:75). Asimismo, en el 2014 Tenosique volvió a ser impactado en materia de política migratoria cuando el expresidente Enrique Peña Nieto implementó el Programa Integral Frontera Sur con el que buscaba «desarrollar una frontera próspera, moderna, segura, con flujos migratorios ordenados y con pleno respeto a los derechos humanos» (Gutiérrez, 2017:75).

En 2011 un grupo de frailes franciscanos en el municipio de Tenosique, Tabasco, se organizaron para crear La 72, Hogar-refugio para personas migrantes (La 72), con la finalidad de proporcionar hospedaje, comida, atención médica y asesoría jurídica a miles de migrantes que cruzan la frontera México-Guatemala. En otras palabras, generaron mecanismos de resistencia política para defender a los migrantes centroamericanos del abuso de las autoridades mexicanas y de los 
grupos delincuenciales. Por ese lugar, conocido como El Ceibo (véase mapa 1), transitan transmigrantes de Guatemala, Honduras, Nicaragua, Costa Rica, Cuba, Brasil, Colombia, y de lugares tan distantes como China, Haití o Senegal. En esa frontera global la población transmigrante es presa de grupos de la delincuencia organizada como Los Zetas, Los Caballeros Templarios, el Cartel del Golfo y La Familia Michoacana. Algunos grupos, no menos violentos, son la banda o pandiIla transnacional de la Mara Salvatrucha y hasta una pequeña red de motociclistas locales armados con pistolas. Bolio et al. (2019) señalan que

Tenosique es una de las principales fronteras de acceso para diversos grupos de migrantes centroamericanos en situación de pobreza y exclusión social, con lo cual inician la búsqueda de un supuesto desarrollo occidental en los Estados Unidos. Este municipio se caracteriza por un flujo migratorio importante donde muchos migrantes indocumentados emprenden el inicio hacia el sueño de superación promovido por el propio contexto globalizador actual. Acorde con el Informe Tenosique (2011:12), el refugio La 72 ha denunciado "la violencia ejercida por el Instituto Nacional de Migración (INM) contra las personas migrantes. Ha sido documentado que algunos agentes federales del INM participan en verdaderas cacerías inhumanas y salvajes de personas migrantes. Los agreden física y verbalmente. Los funcionarios no cuentan con ninguna capacitación en derechos humanos" (Bolio et al., 2019:92).

Mapa 1. Frontera México-Guatemala

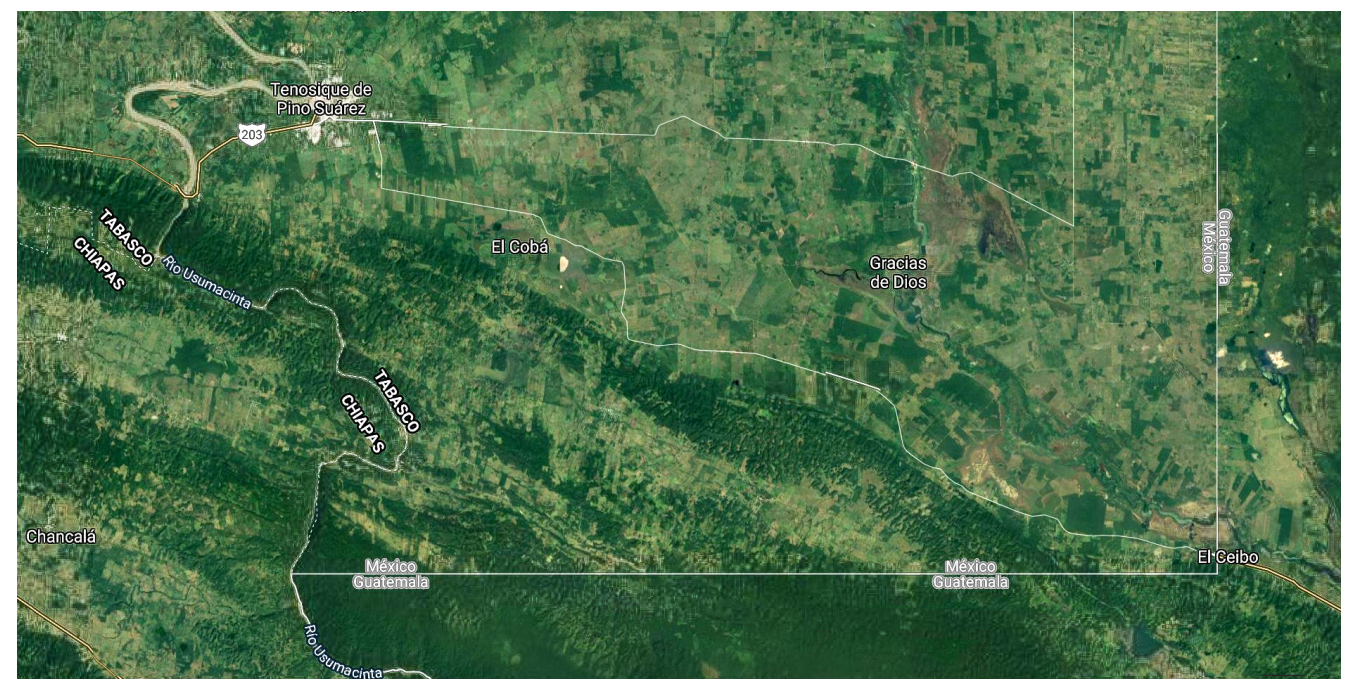

Fuente: Elaboración propia a partir de Google Maps, 2020. 
Esta organización confesional adoptó el nombre de La 72 por el evento crítico suscitado en San Fernando, Tamaulipas, donde en agosto de 2010, 72 transmigrantes fueron asesinados brutalmente por negarse a pagar a Los Zetas una cuota para ser liberados en su tránsito hacia los Estados Unidos de América. En un informe de la BBC News se relata cómo:

58 hombres y 14 mujeres fueron llevados a una bodega abandonada en un sector rural de San Fernando, a casi cien kilómetros de la frontera con los Estados Unidos de América, donde fueron vendados y obligados a apoyarse contra un muro, para luego, ser baleados. En ese lugar quedaron amontonados 24 hondureños, 14 salvadoreños, 13 guatemaltecos, cinco ecuatorianos, tres brasileños, un indio y 12 cuerpos sin identificar (Pérez, 2015).

De ese espacio trágico y violento, dos personas lograron escapar: una mujer y un hombre ecuatoriano cuya narrativa permitió la reconstrucción de ese drama social. El nombre de La 72 simboliza la resistencia frente a las prácticas de dominación que ejercen los funcionarios del municipio de Tenosique, del INM, de los mareros, de las redes de motociclistas, de la policía local y de actores de la delincuencia organizada.

La 72 está integrada por laicos que trabajan en la administración del centro, en el fondeo para recaudar recursos, en la organización de la cocina, en el grupo de guardias, en la coordinación con el grupo de voluntarios, en el seguimiento con un grupo de abogados que asesoran a los migrantes y en la canalización con Médicos Sin Fronteras. Ahora, aunque los abogados y los médicos son organizaciones independientes a La 72, se les han otorgado espacios para que se instalen dentro de la casa. Esto resulta significativo en el marco organizacional de La 72, pues para poder colaborar en las diversas actividades y responsabilidades no se requiere ser creyente, basta con la actitud colaborativa para ayudar en la residencia de los transmigrantes.

En esta casa encabezada por fray Tomás González y la orden de franciscanos, en su mayoría dan refugio a transmigrantes centroamericanos que salen de sus países de origen debido a la fragilidad de sus economías y, en los últimos tiempos, por la violencia y los conflictos político-electorales como en el caso de Honduras. Ese grupo de religiosos se organizó para apoyar y proteger a la comunidad transmigrante de la trata de personas, de la extorsión y de la violencia en el tránsito por México. De un reportaje de José Gil Olmos extraemos una narrativa de los sacerdotes liderados por fray Tomás: 
La 72, así, con género femenino, queremos ser una casa acogedora donde las personas migrantes no sólo encuentren pan y cama para dormir, sino que encuentren el abrazo solidario, la bendición materna, el lugar donde las mujeres embarazadas den a luz y donde los sueños de una vida mejor se empiecen a hacer realidad. Es una gran vergüenza para nosotros que las y los migrantes encuentren en nuestro país sufrimiento y muerte. Nos negamos a aceptar la muerte de los 72 en San Fernando, Tamaulipas, y por eso desde este rincón empobrecido y olvidado, gritamos y exigimos que el gobierno mexicano frene el holocausto migratorio. Desde este lugar nuestra mirada y nuestra voz también se dirigen a las víctimas vivas, familiares de los 72, y que sirva como un abrazo permanente de consuelo el saber que, al entrar a México por la frontera sur, en Tabasco hay un altar-hogar en honor de las víctimas que derramaron su sangre en agosto de 2010 (Gil, 2015)

Con esta visión, los franciscanos han implementado una estrategia de resistencia para interpelar todos los ejercicios de abuso de poder, aunque esto ha tenido un alto costo porque los grupos delincuenciales los han rafagueado, baleado, con armas de alto poder. De igual forma, fray Tomás ha recibido amenazas de muerte por su activismo político de defensa en contra de las arbitrariedades y violaciones a los derechos humanos de los migrantes. Pese a esto, la violencia no ha detenido el trabajo que los frailes realizan con los migrantes para alertarlos y concientizarlos sobre los peligros que pueden encontrar en Tenosique con las autoridades y los «malandros». Quizá las armas más poderosas de fray Tomás sean su megáfono para protestar en contra de la policía, de los agentes de inmigración y de las autoridades municipales; su guitarra con la que interpreta canciones de los oprimidos; y sus huaraches con los que marcha acompañado de los transmigrantes de Tenosique hacia la capital del estado o incluso a la propia Ciudad de México. En el contexto de las fiestas decembrinas, por ejemplo, fray Tomás, modificando la letra de las letanías, pide posada en las oficinas de la Procuraduría General de la República (hoy Fiscalía General de la República), del Ayuntamiento Constitucional o del Instituto Nacional de Migración no para San José, la Virgen María o el Niño Jesús, sino para los migrantes:

En nombre de la justicia, busco apoyo solidario, luces vengo de noche, vengo de indocumentado. No vengas con tu miseria, 
ni vengas a molestar, te voy a echar a la migra, para que te mande a volar.

Soy centroamericano, busco acá trabajar, voy p’al otro lado, mira mi necesidad (Castro G., 2016).

En el contexto de la Semana Santa de 2014, también organizó la caravana migrante para apropiarse del viacrucis y resignificarlo como un espacio simbólico para demandar atención contra la violencia de la que son presa los migrantes.

Sin plan previo, con una agenda que se construye noche a noche en asambleas donde los únicos que deciden son los centroamericanos que integran la caravana migrante que este miércoles llegó al Distrito Federal, la larga marcha de los indocumentados empezó en Semana Santa, en la frontera de Tabasco con Guatemala, con la idea de hacer un viacrucis diferente, una acción de desobediencia civil; algo fuerte que llamara la atención sobre la violencia que se arrastra por años, pero que en los dos recientes se ha recrudecido a niveles intolerables, explica fray Tomás González, director del albergue La 72, de Tenosique, quien organiza desde hace cuatro años ese ritual con ingredientes de religión y protesta. Nunca habían llegado tantos y de tan lejos. Este miércoles fueron 18 los autobuses urbanos que hicieron su aparición triunfal en la glorieta del Ángel de la Independencia, a las 13:30 horas. Más de mil personas descendieron de los vehículos; hombres y mujeres que cruzan el territorio nacional desde remotos poblados de Honduras, El Salvador o Guatemala, sin papeles, sin dinero, empujados sólo por la extrema necesidad de trabajar. Medio centenar son mujeres y muchas traen niños, incluso de brazos. Otros menores viajan solos (Petrich, 2014).

Cuando un migrante ingresa a La 72, los voluntarios lo reciben solidariamente y le hacen un conjunto de preguntas protocolarias para descartar que sean integrantes de algún grupo de la delincuencia organizada. Acto seguido, los voluntarios le explican todo lo que pueden recibir en la casa, como atención médica con Médicos Sin Fronteras, por ejemplo, para curarles las heridas que pudieran presentar en los pies, infecciones estomacales o para atender partos. También le informan sobre la asesoría legal del Área de defensoría, sobre los alimentos, el refugio y sobre el acceso a minutos de internet para comunicarse con sus familiares. 
La 72 está organizada bajo un conjunto de reglas estrictas que permiten una convivencia armoniosa basada en relaciones de confianza, respeto y reciprocidad:

1.-Cuando llega una persona a La 72, después del registro, se le canaliza con la encargada para la entrevista.

2.-En la entrevista se les explica el funcionamiento del módulo, las reglas, sobre las reuniones, las actividades grupales y las consecuencias de no cumplirlas.

3.-Después de la orientación, la persona decide si quiere estar o no en el módulo. 4.-Si la persona está de acuerdo en permanecer en el albergue, se le asigna una cama que no se permite intercambiar con otras personas. Si la persona quiere cambiar su cama es necesario el permiso del coordinador del módulo y de la encargada.

5.-No se les permite a las personas dormir juntas en la misma cama.

6.-Tampoco está permitido el ingreso de personas ajenas al módulo.

7.-No se permite fumar mariguana o tomar bebidas alcohólicas.

8.-No se pueden tener relaciones sexuales dentro del módulo.

9.-A cada persona se le asigna un día de limpieza y el sábado todos están obligados a participar en una a fondo.

10.-Todas las personas deben participar en reuniones del módulo.

La entrevista es fundamental pues a partir de ahí se construye la confianza entre la persona migrante y la encargada. Con estas reglas de convivencia los migrantes reciben un acompañamiento integral y el grupo de voluntarios siempre está al pendiente de su bienestar en materia de salud física, mental, emocional y de su estatus legal.

La 72 tiene cero tolerancia con las prácticas violentas dentro y fuera de la casa, al llegar a este espacio lo primero que se hace con las personas migrantes es informarles sobre las reglas de la casa. La primera regla y más importante es que no se permite ningún tipo de violencia a ningún sector de la población migrante. Cero violencia hacia las mujeres considerando cualquier tipo de piropo o trato lascivo; cero violencia hacia el módulo LGBTTTI considerando cualquier tipo de insulto como "maricón", "marica", "culero", "put@" o trato lascivo; cero tolerancia a golpear niños, aunque sean los responsables o padres del menor; cero tolerancia a los traficantes de personas como coyotes, polleros, enganchadores. En este sentido a La 72 le interesa que todos los sectores vivan pacíficamente dentro de la casa, así que en el caso de este módulo el acompañamiento que se les da es íntegro, se está al pendiente de la totalidad de las personas y su bienestar todos los días: su salud física, salud mental y emocional, su proceso migratorio y también su salud espiritual (Castro G., 2018). 
Durante las entrevistas de llegada y en el trabajo grupal, las encargadas logran inferir la problemática que enfrenta cada migrante. Con frecuencia invitan a las personas de la comunidad a que acudan a terapias con el psicólogo de Médicos Sin Fronteras. Además, imparten charlas sobre enfermedades de transmisión sexual, sobre las consecuencias de contraer el virus del VIH, y sobre las ventajas y desventajas de los tratamientos hormonales.

La casa se mantiene con los recursos que proporciona la orden franciscana y con donaciones en especie del mercado municipal: frijoles, arroz, col, lechugas, berenjenas, calabazas, plátanos, chicharrón y en ocasiones carne de pollo, cerdo o res. De igual forma, el trabajo desinteresado de los voluntarios es central para la elaboración de la comida, para atender a los recién llegados, apoyar el traslado de enfermos a los hospitales, para recoger todos los productos donados por la gente de Tenosique, para conseguir agua potable, para la realización de talleres, para la organización de festivales como el de la cultura garífuna y para coordinar los trabajos de limpieza. Los voluntarios son jóvenes que provienen de diversos lugares de México, de los Estados Unidos, Alemania, Argentina, España, entre otros.

La 72 es una Casa del Migrante administrada por la Provincia Franciscana "San Felipe de Jesús" en el Sureste de México; es una organización de la sociedad civil, sin fines de lucro. Se dedica a la atención integral a las personas migrantes y refugiadas que se internan a México por la frontera de Tenosique, Tabasco, uno de los puntos más conflictivos y peligrosos en la ruta migratoria. Nuestra tarea fundamental es acoger, consolar, acompañar al ser humano vulnerable, en este caso las personas migrantes y refugiadas, tan castigadas por los sistemas extractivos vigentes. Durante el año 2016 atendimos a 13,895 personas, en su gran mayoría de origen centroamericano. Durante estos años hemos evolucionado como casa de atender a personas migrantes en tránsito a personas refugiadas que huyen de la violencia en Honduras y El Salvador que vienen a México para pedir protección internacional, literalmente para salvar sus vidas (La 72, s.f).

En una reflexión muy estimulante, Eric Luna, estudiante ${ }^{3}$ y voluntario de La 72, se plantea que:

Ser voluntario implica un cierto gasto económico personal, pero entraña un significado de autorrealización que se comparte socialmente con un grupo. Al

\footnotetext{
${ }^{3}$ Posgrado en Ciencias Antropológicas de la Universidad Autónoma Metropolitana-Iztapalapa.
} 
poder hablar con las compañeras y compañeros voluntarios, coincidíamos en lo "desgastante" que es económicamente sostener un acto de esta naturaleza. Muchas de las compañeras que llegaron del extranjero y del país (México) aceptaban que se les facilitó estar en La 72 gracias a financiamientos a través de becas u otros apoyos similares. Solamente una de ellas se definio como una "trota mundo". Por nuestra parte, Armando y yo coincidimos en que nuestros ahorros como trabajadores fue lo que nos permitió estar en la casa de migrantes. Aunque las características personales y sociales requieren de un análisis más detallado, algo que sobresale fue que todos contábamos con un grado universitario, o al menos estaban por obtenerlo; además previamente habíamos trabajado profesionalmente y nos encontrábamos en una posición social favorable para desplazarnos y disponer de tiempo (Luna, 2018:40).

Hasta el presente año en La 72 se han recibido a 74835 migrantes, por lo que los recursos que ingresan por la vía de la orden de los franciscanos, las donaciones en la página web de esta organización, las donaciones del mercado local y de los vecinos, siempre son insuficientes para cubrir las necesidades de alimento generadas por la población en tránsito. Por esta razón, el 25 de abril de 2017, La 72 inició el proyecto denominado Laudato Sí. Techo, Trabajo, Tierra. Granja Agroecológica para migrantes y refugiados, cuyo propósito es ofrecer trabajo para quienes residen ahí en espera de la resolución de su proceso migratorio y para proveer alimento para los miles de migrantes que cada año transitan por la casa albergue.

Los franciscanos tomaron este nombre de la carta encíclica emitida por el papa Francisco que significa: Alabado seas, mi Señor. Esta plantea la necesidad de proteger una casa común que incluya la preocupación de unir a toda la familia humana en búsqueda de un desarrollo sostenible e integral. Asimismo, en esta carta encíclica se convoca a un nuevo diálogo sobre cómo la humanidad está construyendo el futuro del planeta y al desafío ambiental que vivimos, es decir, se propone un movimiento ecológico que desde una concientización de la sociedad busque el cuidado del entorno, de la biodiversidad, del agua, del crecimiento poblacional desproporcionado, de mitigar los efectos de la contaminación y del cambio climático. Con base en esta carta los franciscanos de Tenosique buscaron construir una granja autosostenible, que al mismo tiempo proporcione alimentos de manera cotidiana para el abasto de su cocina. 
La 72 opera como una organización de la sociedad civil con una agenda de defensa de los derechos humanos de los transmigrantes. No obstante, simultáneamente puede ser considerada como un hecho social total a la usanza de Marcel Mauss (1971), porque es un espacio con acciones claras en las arenas políticas, en la defensa de los derechos humanos, en la atención psicológica, en la asesoría legal, en el cuidado médico, en la procuración de recursos, en el suministro de alimentos, en facilitar fuentes de empleo y en el proveer servicios religiosos. Al frente de La 72 los frailes franciscanos han implementado un espacio societal autonómico muy eficiente para resistir e interpelar a las acciones legales, políticas, económicas y violentas en contra de los poderes formales o informales que operan en Tenosique.

Un trabajo frontal del hogar-refugio es la lucha incansable en contra de la trata de personas en Tenosique, para lo cual ofrece asistencia a las víctimas en el albergue, servicios de protección y asesoramiento. El esfuerzo ha sido mayúsculo pues a los pocos años de haberse creado, a fray Tomás le informaron que un grupo de la delincuencia organizada había secuestrado a un grupo grande de migrantes y que pretendían llevárselos en La Bestia. Acto seguido, el religioso corrió para interceptar el tren y en un drama social él se le paró de frente sobre las vías mientras la gente de Tenosique le gritaba: «quítese de ahí padre, lo va a matar el tren». Pero el fraile no se intimidó y de manera sorprendente el tren frenó hasta el alto total y en las afueras de Tenosique cientos de migrantes fueron liberados y rescatados.

Es habitual que La 72 participe en situaciones o coyunturas de emergencia y asista a migrantes que fueron violentados. En la Semana Santa de 2015, por ejemplo, una madre hondureña y su pequeña hija fueron balaceadas por grupos de la delincuencia organizada, ambas fueron hospitalizadas y en todo momento los voluntarios las apoyaron. Desafortunadamente la pequeña perdió la vida porque su madre, al estar inconsciente por la gravedad de la agresión, no pudo dar su consentimiento en el hospital para que operaran a su hija. Dramas sociales de esta naturaleza son muy cotidianos para los voluntarios que participan en el proyecto de La 72.

La 72 Hogar-refugio para personas migrantes es un espacio democrático que no hace distinciones entre los transmigrantes que demandan la defensa de sus derechos humanos; no obstante, es importante entender que La 72 es un albergue confesional, es decir, está condicionado y constreñido por una jerarquía de valores, un sistema de ideas y los dogmas de una religión. Como se 
mencionó, está dirigido, organizado y administrado por ministros de culto de la orden de los franciscanos, es decir, forma parte de la religión católica. Pero fray Tomás y los hermanos de la orden le han otorgado un estilo plural al albergue en cuanto a las diversas manifestaciones religiosas, políticas, culturales e, incluso, de género. Esto quiere decir que un migrante de la Iglesia neopentecostal, de la Iglesia bautista, islámica o del movimiento New Age puede tener acceso al albergue, y se le brindan todas las atenciones requeridas. De igual forma, un migrante que se presente como parte de la comunidad LGBTTTI (Lésbico,Gay, Bisexual,Transexual, Transgénero, Travesti, Intersexual) puede tener acceso al albergue y, de hecho, ahí están organizados para recibir a hombres en un dormitorio, a mujeres y niños en otro, y a la comunidad LGBTTTI en otro más.

La 72 es el único albergue católico de atención a migrantes en México que abre sus puertas para atender a integrantes de la comunidad LGBTTTI, a quienes trata con dignidad, a diferencia de otros albergues confesionales que les niegan el ingreso a personas gay o transgénero. La doctrina social cristiana de la mayoría de los sacerdotes de la Iglesia católica, ya sean del clero regular o secular, no acepta relaciones entre personas del mismo sexo y menos aún que adopten niños; por lo que no es extraño que en los albergues católicos se niegue la ayuda a migrantes de la comunidad LGBTTTI. Pero en La 72 existe un ambiente de pluralidad, ecuménico, democrático y de respeto en el sentido más amplio, de hecho, es tan especial la relación de las mujeres transgénero que ahí viven, que juegan y bromean con fray Tomás, hasta el punto de pintarle las uñas de color rosa:

Al fondo del albergue se encuentra un módulo morado con las banderas arcoíris, se encuentra en un segundo piso y en el balcón siempre hay chicas trans sentadas viendo a toda la población con una mirada bastante orgullosa por pertenecer al módulo LGBTTTI de La 72. Casi siempre se están arreglando, pintándose el pelo o la cara, depilándose, tomándose fotos, cantando canciones de Gloria Trevi o la famosa canción "Qué perra mi amiga". La palapa que se apropió la población LGBTTTI queda justo abajo del módulo y es un espacio donde prácticamente siempre hay alguien de la comunidad, no cualquiera puede sentarse en esta, ahí sólo las personas LGBTTTI y sus amigos, no es una regla escrita, pero es una práctica que se sigue con rigor (Castro G., 2017).

Los migrantes de la comunidad LGBTTTI de La 72 viven por semanas o meses en espera de ser reconocidos como refugiados en el país o para tomar 
un receso y luego continuar su recorrido sobre La Bestia, en camiones o caminando hacia los Estados Unidos de América. Cabe mencionar que los migrantes de la comunidad LGBTTTI son obligados a salir de sus países no solo por razones económicas o políticas, sino también por discriminación de género. En su tránsito, algunas mujeres transgénero son violentadas sexualmente, otras más se dedican a la prostitución para obtener recursos, por lo que cuando llegan al albergue se les brinda atención de Médicos Sin Fronteras.

En La 72 la comunidad LGBTTTI tiene sus dormitorios donde abiertamente ejercen su identidad de género a través de murales cuya constante es la bandera del arcoíris. Dentro del albergue no se permite ninguna actitud machista, homofóbica o de discriminación hacia migrantes de la comunidad LGBTTTI; de hecho, todas las personas deben formarse en filas para recibir sus alimentos y posteriormente tienen la responsabilidad de lavar sus platos y cubiertos. Asimismo, todos sin distinción tienen la obligación de barrer y trapear sus dormitorios y los espacios comunes. La 72 promueve valores de equidad entre los migrantes para que ellos sean los promotores de su desarrollo, por esa razón los voluntarios y los responsables de cada programa tratan bien a la gente, pero sin actitudes de conmiseración frente a algún transmigrante. En seguida describimos un drama social donde fray Tomás y transmigrantes hondureños realizaron una acción de resistencia frente a la discriminación de policías municipales de Tenosique.

\footnotetext{
En Tenosique, en la Feria del queso, a un chico que era abiertamente gay le negaron el acceso. La razón que le dieron los policías era que no se permitía la entrada a "ilegales" y mucho menos a "ilegales gay". La 72 obviamente no iba permitir esa absurda respuesta, por lo cual se convocó a toda la población del albergue a participar en una marcha hacia la Feria del queso. Eran unos 60 migrantes y el policía no tuvo más remedio que abrir la puerta. Fray Tomás, la cara de La 72 y fundador del albergue, denunció con un megáfono la actitud soberbia e ignorante de la policía y exigió que el policía que no le había permitido la entrada a este chico se disculpara con él (Castro G. 2017).
}

Muchas de las acciones políticas que realiza fray Tomás en el albergue operan desde los discursos ocultos, es decir, los religiosos, voluntarios y laicos concientizan a los migrantes sobre sus derechos al ingresar a México. No obstante, en la situación descrita en torno a la Feria del queso, fray Tomás puede ser el actor más aguerrido y empoderado para organizar a toda la población del 
albergue y para hacer explícitos sus discursos públicos de resistencia en manifestaciones contra la policía municipal por sus acciones frente a los sectores más vulnerables.

Desafortunadamente, la mayoría de los integrantes de la comunidad LGBTTTI de La 72 fueron víctimas de la discriminación y la violencia en sus países de origen y con frecuencia fueron presa del delito durante el trayecto. Por eso es muy importante el trabajo que realizan los coordinadores y encargados del albergue para valorar la situación de las personas del módulo. A continuación describimos una conversación entre una voluntaria y un grupo de migrantes, donde la primera realiza un trabajo medular de contención y apoyo frente a la violencia experimentada por un transmigrante guatemalteco.

En la navidad del 2016 hice una estancia de un mes en La 72, recuerdo que mi primera tarea fue vender ropa al bazar para juntar dinero, éramos tres voluntarias y un muchacho de pelo chino, una nariz afilada, era de Guatemala. Nuestra conversación fluía alrededor de nuestro país de origen, nuestros idiomas y nuestro interés sobre el albergue. Este muchacho se llama N, sabe algunas palabras en maya, su padre fue asesinado por sus tíos por el interés de unas propiedades, lo corrieron de su casa después de haber sido violado por alguno de sus tíos en su adolescencia. N dice que su madre lo odia, "preferiría haber parido una piedra a un culero" siempre que él volvía a su casa para ver si lo dejaban regresar, su madre hacía comentarios de este tipo (Castro G., 2016).

Como se puede apreciar, en el módulo de la comunidad LGBTTTI se genera un ambiente muy controlado que estimula relaciones solidarias y la confianza entre las personas. Sin embargo y, a pesar de que los frailes tratan de incentivar un ambiente de respeto ante las diferencias culturales, la diversidad sexual, las preferencias religiosas y las ideas políticas, lo cierto es que los transmigrantes heterosexuales portadores de culturas con valores machistas y patriarcales son intolerantes frente al tema de la sexualidad y en consecuencia las agresiones verbales se hacen presentes. Esto quiere decir que, al interior del albergue, así, de manera oculta o en ocasiones pública, como nos alerta Sherry Ortner (1995) en sus reflexiones en torno a no construir narrativas idílicas de la resistencia, se ejerce una discriminación y violencia sobre las personas de la comunidad LGBTTTI. En el contexto de las comidas, por ejemplo, los cocineros se refieren a las mujeres transgénero utilizando palabras desagradables y 
de doble sentido. O en el marco de la seguridad, también, los guardias hablan mal de la comunidad LGBTTTI para desprestigiarla.

Al interior de la comunidad LGBTTTI también se ejerce violencia simbólica, en particular a través de insultos verbales, aunque en momentos álgidos terminan en golpes. Las mujeres transgénero no quieren vivir en la misma habitación con hombres homosexuales, quienes a su vez no quieren vivir con ellas y las discriminan porque argumentan que son muy extrovertidas. De igual manera, al interior del grupo de las mujeres transgénero en ocasiones los celos conducen a la violencia.

Algunos integrantes de esta colectividad han experimentado el consumo de drogas y alcohol, sobre todo cuando entran en periodos de depresión, estrés y angustia. También algunas mujeres transgénero y hombres homosexuales se han dedicado a la prostitución debido a las dificultades derivadas de estigmas sociales, a la falta de oportunidades y a la discriminación por asumir de forma abierta su diversidad. No obstante, una vez que llegan al albergue la situación cambia porque está prohibido el consumo de drogas, alcohol, y ejercer la prostitución dentro de las instalaciones.

Las chicas trans siempre buscan verse bien, por eso aunque solo traigan una maleta procuran que entre esas pocas cosas con las que viajan, haya por lo menos un par de tacones y ropa súper stretch. He conocido a chicas que suben al tren con tacones lo cual representa un riesgo mayor porque para subirse al tren necesitan mucha agilidad y unos tacones pueden hacer que se tropiecen o caigan del tren. Defender la belleza en un contexto tan violento es un acto de resistencia, aunque también el verse bien puede ser un tipo de empleo ya que muchas de las chicas se han dedicado y se dedican a la prostitución. Daryl de Guzmán era la encargada del módulo LGBTTTI, comenta que "las chicas trans, muchas de ellas se dedicaban a este tipo de trabajo por falta de oportunidades, por discriminación o se acostumbraron haciendo esto por muchos años, creciendo en la calle. También los hombres homosexuales" (Castro G., 2018).

En La 72 las mujeres transgénero habitualmente se visten bien, se maquillan y tienen sus comportamientos pactados desde donde logran reproducir una identidad de género, que en el contexto de exclusión se convierte en un repertorio político que les permite posicionarse para defenderse de la violencia de género. Por medio de su manera de vestir reproducen valores, sentimientos, utopías y anhelos sobre cómo quieren socializar en la cotidianeidad. En las for- 
mas de vestir manifiestan su opción de vivir su diferencia a pesar de las críticas y los señalamientos de sectores que se oponen a ellas. Por esta razón, resulta entendible que una mujer trans trabaje en los espacios más ordinarios, agrestes y descorteses utilizando tacones.

E es una chica trans que subió al tren, cuando este se escuchaba venir del sur ella salió corriendo, en ese momento ella usaba unos tacones altos; muchas veces cuando llega el tren los voluntarios vamos con fray Tomás a documentar y observar cuánta gente se está subiendo, solo vamos con el equipo de La 72, no podemos ir solos porque es una zona de alto riesgo por la delincuencia local. Cuando E corrió hacia el tren los tacones obviamente le impedían correr rápido por lo que se los quito y corrió descalza, esa es la imagen que no se me olvida, ella con sus tacones en una mano y con la otra deteniéndose de las escaleras del tren para subirse, no sé nada de ella (Castro, G. 2017).

En este sentido, los migrantes LGBTTTI que residen en La 72 han encontrado en el albergue un repertorio para protegerse de la exclusión por ejercer su identidad de género. Pero pasan por un proceso de socialización a través de las reuniones de grupo, de las pláticas con los médicos y psicólogos de Médicos Sin Fronteras, de las asesorías legales y de las charlas con los frailes, esto las dota de información y conocimientos que les permiten el empoderamiento para que se defiendan en términos de su estatus legal, de su salud, o de su búsqueda de equidad de género.

Na es una chica trans que reside en Estados Unidos de América y va con mucha frecuencia a Tenosique a trabajar como voluntaria en la comunidad LGBTTTI. Ella, acompañada de su novio y otros artistas, desarrollan talleres de manualidades, sesiones de fotos, talleres de belleza y otras actividades donde se apoyan de herramientas del arte, acompañándose de reflexiones para trabajar con las emociones, los miedos y los sentimientos de esta comunidad. Es una chica trans que cuenta con experiencia trabajando con la comunidad LGBTTTI para que tengan un autocuidado, seguridad y amor propio. Na se gana la confianza de las chicas trans con esas actividades y al platicar con ellas generan reflexiones sobre el trato que debería tener la comunidad LGBTTTI, pero siempre intentando que el orgullo y el ánimo de estas chicas trans se incremente. Al ser una chica trans, tiene más incidencia porque ella les habla desde su propia experiencia (Castro G., 2018). 
Las mujeres trans ven transformados sus repertorios de acción en su paso por La 72 a través de talleres y pláticas informales donde descubren los derechos humanos que pueden ejercer en México. Se transforma su matriz consciente e inconsciente de símbolos y signos que portan conocimientos e información, sentimientos, valoraciones, utopías y veleidades sobre el ejercicio del poder, es decir, su cultura política. El caso de Paola (una mujer trans hondureña) fue analizado de manera sugerente por Víctor Hugo Gutiérrez Albertos, quien explora sus prácticas de resistencia en su paso por La 72:

Paola consiguió en La 72 repolitizar muchas discusiones y vincularlas al tema de justicia social y su relación con la eliminación de la discriminación y la emancipación trans. La 72 fue incorporando estas valiosas aportaciones en su constante camino de insurgencia y de construcción de nuevas prácticas y modos culturales diversos de pensar y actuar. En este proceso reformularon las estrategias encaminadas a la transformación y supresión de múltiples mecanismos de dominación social y cultural. El compromiso intercultural que asume el hogar-refugio parte de que su construcción es colectiva y "desde abajo", ya que su accionar se fundamenta en la comunidad donde se encuentra y en las personas migrantes que llegan. De esta manera, permiten visibilizar una parte significativa de la situación de sometimiento y emergencia humanitaria de las personas migrantes pertenecientes a las diversidades sexuales en México. Este cambio de paradigma crea una perspectiva de emancipación "que se puede hacer concreta en la praxis interdiscursiva entre culturas que sostienen sus fundamentos epistemológicos y sociopolíticos en la intersubjetividad, con miras a orientar un entendimiento que puede ser universalizado a favor de la plurivisión" (Díaz Montiel 2008,147) de formas de vida que escuchan las voces de las personas trans. Este posicionamiento intercultural no heterenormativo y contra-hegemónico que persigue La 72, permitió a Paola continuar desarrollando sus destrezas y habilidades de reivindicación y transformación social basados en la responsabilidad y solidaridad. Cada vez que posiciona en diferentes espacios la situación de vulneración de los Derechos Humanos de las personas migrantes trans, hace un llamado a la sociedad mexicana a volver a creer en la otra y asumir a la que está fuera de cada persona (Gutiérrez, 2017: 89-90).

La situación social en el contexto de tránsito es sumamente agreste para la población migrante que es excluida por no tener una seguridad en su estatus migratorio, por obtener trabajos muy precarizados y por sus rasgos culturales; pero el transmigrante LGBTTTI es doblemente excluido por ejercer su identidad de género. Sin embargo, frente a los poderosos, a la policía, a las autoridades de inmigración y a los grupos delincuenciales, las mujeres transgénero y los 
hombres homosexuales han desarrollado discursos ocultos y comportamientos ritualizados que les permiten resistir en mejores condiciones. Para estas estrategias el papel del voluntariado ha sido central, porque por medio de la participación política de mujeres trans como $\mathrm{Na}$, La 72 recibe artistas y activistas de los Estados Unidos de América para realizar cursos, talleres y pláticas para sensibilizar y concientizar a los miembros de la comunidad LGBTTTI en temas de violencia en el tránsito, defensa de derechos humanos, arte, salud y belleza. En 2017, por ejemplo, se realizó un taller de grabado con la idea de que los transmigrantes pudieran plasmar algo que fuera de su interés. Los temas más recurrentes se referían a elementos de sus culturas -como la garífuna-, alimentos que extrañaban, nostalgia por los lugares, sus problemáticas, las banderas de sus países, imágenes sobre México y sus experiencias en el contexto del tránsito hacia los Estados Unidos de América. En este sentido, llama la atención un grabado realizado por Nikky, una mujer trans, quien reproduce un discurso público que la empodera en relación con su identidad de género (véase imagen 1). Esto resultó significativo porque, aunque en La 72 se promueve un ambiente de pluralidad y respeto, lo cierto es que aún se reproducen discursos ocultos patriarcales que vetan la diversidad de género.

Imagen 1: Grabado Mi diversidad no tiene frontera, realizado por Nikky, 2017.

Técnica de grabado en linóleo 15 × $20 \mathrm{~cm}$.



Fuente: Castro, 2017. 
Dicho lo anterior, la información, los conocimientos, los sentimientos y las utopías de las organizaciones de la sociedad civil fortalecen a la comunidad LGBTTTI con miras al empoderamiento en términos de sus identidades de género para migrar a través de rutas más seguras y para construir repertorios de resistencia que posibiliten la defensa de sus derechos humanos.

Como hemos visto, La 72 es una organización de la sociedad civil dedicada a la defensa de los derechos humanos de los migrantes. Es una organización compleja que le proporciona a los transmigrantes alojamiento, alimentación, atención médica, trabajo, atención legal, información sobre las rutas migratorias, asesoramiento para retornos seguros y defensa de sus derechos en el tránsito.

\section{Conclusiones}

En México, la violencia hacia los transmigrantes centroamericanos se ha expandido al nivel de desapariciones, extorsiones, secuestros, golpes, abusos sexuales y asesinatos. Esta situación ha estimulado la emergencia de organizaciones de la sociedad civil como La 72, Hogar-refugio para personas migrantes, administrada y organizada por un grupo de frailes franciscanos que emprendieron la tarea de apoyar y defender la integridad de los transmigrantes, incluso arriesgando su propia seguridad frente a grupos de la delincuencia organizada. Asimismo, por apoyar a migrantes de la comunidad LGBTTTI los frailes franciscanos también se colocan en una situación de vulnerabilidad al interior de la iglesia católica, pues hay que recordar que la Doctrina Social Cristiana no acepta la homosexualidad y menos aún la adopción de niños por parejas del mismo sexo. Sin embargo, a contracorriente, los frailes franciscanos ayudan a los migrantes de la comunidad LGBTTTI, aunque ellos siempre sean observados por la jerarquía de la Iglesia católica. Ahora, con la postura de ayudar al más necesitado, los franciscanos construyen un sólido argumento para que dentro de su trabajo pastoral continúen su defensa del transmigrante, incluidos los pertenecientes a la comunidad LGBTTTI.

Como se explicó en este artículo, existe una fuerte vinculación entre mujeres trans originarias de Centroamérica y de los Estados Unidos de América, mediada por La 72, factor medular para el empoderamiento de las primeras, porque el movimiento LGBTTTI norteamericano ha sido un referente en la de- 
fensa de los derechos humanos desde la década de los setenta a través de debates, argumentaciones, controversias, disputas y amparos legales. Esto le ha dotado de un sello novedoso y progresista al movimiento LGBTTTI en la Unión Americana, no solo en temas de prevención del VIH, sino en un sentido más amplio en la expansión de los derechos humanos. En oposición, el movimiento en Centroamérica presenta un déficit en términos de la formación de organizaciones de la sociedad civil, en una presencia sólida en la arena pública, en la construcción de una narrativa cultural, en las negociaciones para mejorar los espacios de salud pública, en las estrategias para revertir la violencia por condiciones de género y en la defensa de los derechos humanos.

Con sus experiencias, luchas y nuevos saberes las mujeres trans centroamericanas han ido construyendo una narrativa muy poderosa para resistir a la cultura de género hegemónica. En este proceso el movimiento LGBTTTI norteamericano les ha dotado nuevos repertorios de acción, pero sin duda un espacio que ha posibilitado un nuevo ambiente de convivencia es $L a 72$, al proporcionarle a las mujeres trans un apoyo integral que va desde la atención de la salud, asesoría legal, alimentación, trabajo, hasta una residencia segura. Por supuesto, para ellas hay costos muy altos en términos de sus subjetividades, de su sistema de valoración, de su jerarquía de prácticas, de sus relaciones sociales, de sus transformaciones corporales, su capital social y sus prácticas políticas. En este proceso las mujeres trans pasan por una doble exclusión: primero desde las relaciones asimétricas interiorizadas en las culturas de sus países de origen; y después desde las políticas atropelladas por las instituciones del Estado mexicano, la dominación de los grupos delincuenciales y de algunas autoridades, e incluso por las narrativas y la explotación de algunos actores en México.

La información, el conocimiento y la asesoría son armas sutiles pero significativas para que los transmigrantes centroamericanos logren una inserción más segura en espacios como Tenosique. En tanto que las manifestaciones, las marchas, las declaraciones en medios impresos y electrónicos, la participación en foros nacionales e internacionales y el cabildeo con autoridades son armas poderosas para que los frailes, en particular fray Tomás González, tengan la capacidad de incidir en las agendas que atañen a los transmigrantes.

Los transmigrantes son actores creativos que establecen relaciones sociales, laborales, culturales y políticas en más de una localidad, región o país, constituyendo redes a través de las cuales acceden a información, seguridad y mercados laborales. Los mecanismos que utilizan para decidir los posibles lu- 
gares de inserción están condicionados por las redes sociales de parentesco, amistad y paisanaje. Esto les permite acceder a información, recursos y apoyos para construir circuitos migratorios más seguros, confiables y duraderos. Pero en su tránsito por México los migrantes centroamericanos se han enfrentado a la violencia, a la violación de sus derechos humanos, a los secuestros, a las extorsiones, a las amenazas, a las desapariciones, al trato de personas y al poder de grupos delincuenciales y de las propias autoridades del Estado mexicano. No obstante, la participación de las organizaciones de la sociedad civil como La 72 les ha posibilitado espacios de refugio, información compleja, alimento, asesoría legal, trabajo y atención médica, factores que les han proporcionado herramientas y repertorios para matizar el ejercicio del poder.

Otra tarea importante ha sido apoyar a migrantes que han sido violentados en sus derechos humanos y a pesar de las situaciones de violencia en sus lugares de origen, deciden retornar con sus familias. Para esto, La 72 realiza un seguimiento cercano en las instalaciones del INM, para garantizar que los migrantes retornados realicen sus viajes en las mejores condiciones.

Con frecuencia en el hogar-refugio se organizan talleres de arte, festivales de la cultura garífuna, campañas de información sobre transmigrantes y los trabajos de La 72 en redes sociales, pláticas sobre el tránsito por las rutas ferroviarias, carreteras y caminos, pláticas sobre las ciudades más peligrosas en los trayectos, sobre la municipalidad de Tenosique, seminarios internacionales donde los integrantes del albergue exponen sus problemáticas, pláticas de salud y sobre los derechos humanos de los migrantes.

Un proyecto muy prometedor es la creación de Laudato Sí. Techo, Trabajo, Tierra. Granja Agroecológica para migrantes y refugiados, mejor conocido entre los migrantes como "La granjita». En este espacio productivo los migrantes que deben permanecer durante estancias prolongadas para esperar algún documento legal del INM, obtienen trabajo para abonar en los insumos que ingresan al albergue.

La 72 a través de una alianza con Médicos Sin Fronteras garantiza atención médica para los migrantes que residen en el albergue, por ejemplo para curaciones de heridas en los pies, infecciones respiratorias, asistencia a mujeres embarazadas o la canalización a servicios hospitalarios cuando alguien lo requiere. Asimismo, en una alianza con un grupo de abogadas formadas en la Universidad Iberoamericana apoyan en conflictos civiles y penales, en la regulación migratoria, en trámites de residencia y asistencia legal a refugiados. 
La Cuarta Transformación planteó que implementaría políticas migratorias donde los derechos humanos de los migrantes que transitan por nuestro país estuvieran resguardados, pero los cierto es que en el marco del proceso de reelección del presidente Donald Trump y la aprobación del T-MEC, el presidente Andrés Manuel López Obrador fue condicionado para construir un muro en la frontera sur con la presencia de la Guardia Nacional. Este complejo escenario ha llevado al gobierno federal mexicano a implementar políticas restrictivas en materia de migración, donde los derechos humanos de los centroamericanos que transitan por nuestro país se han visto violentados. En este tenor, organizaciones de la sociedad civil como La 72 están atendiendo y dando apoyo a los migrantes en tránsito, de hecho, en este artículo hemos mostrado cómo dicho albergue es una institución total que vela por su alimentación, hospedaje, salud, derechos humanos, derechos políticos y asesoría legal. Asimismo, para atender la agenda migrante La 72 ha generado procesos de resistencia con los repertorios de los discursos ocultos y públicos para incidir e influir en actores muy poderosos como las organizaciones delincuenciales, la policía municipal, el presidente municipal de Tenosique y los funcionarios del Instituto Nacional de Migración.

\section{Bibliografía citada:}

Adams, Richard. (1978). Energía y estructura. México: Fondo de Cultura Económica.

Assies, Willem. (2003). Gobiernos locales y reforma del Estado en América Latina. Zamora: El Colegio de Michoacán, A.C.

Bolio Ortiz, Juan Pablo, Héctor Joaquín Bolio Ortiz y Kiry Rebeca Vences Solis. (2019). De migrantes a desamparados. Estudio de los migrantes indocumentados en la frontera Petén-Tabasco. Revista LOGOS CIENCIA \& TECNOLOGÍA, 11 (1), enero-marzo. Disponible en: https://revistalogos.policia.edu.co:8443/index.php/rlct/article/ download/712/html_1?inline=1

Casillas Ramírez, Rodolfo y Rodolfo Córdova Alcaraz. (2018). Un vuelco de timón: Prioridades y estrategias para la migración en tránsito. México: Centro de Investigación y Docencia Económicas.

Castro Domingo, Pablo. (2015). Procesos migratorios indígenas en el Estado de México. Revista Electrónica Nova Scientia, 7 (2), pp. 622 - 643.

Castro Domingo, Pablo. (2013). Mercado de suelo y resistencia política. Cuicuilco, (58), septiembre-diciembre, pp. 59-76. 
Castro Domingo, Pablo y Luis Rodríguez Castillo. (2009). Antropología de los procesos políticos y del poder. Alteridades, 19 (38), pp. 107-127.

Castro Garcés, Ana Paula. (2016). Notas de campo de Tenosique. México. [ms].

Castro Garcés, Ana Paula. (2017). Notas de campo de Tenosique. México. [ms].

Castro Garcés, Ana Paula. (2018). Notas de campo de Tenosique. México. [ms].

Cohen, Jean y Adrew Arato. (2002). Sociedad civil y teoría política. México: FCE.

Comaroff, Jean y John Comaroff (eds.). (1999). Civil Society and the Political Imagination in Africa: Critical Perspectives. Chicago: University of Chicago Press.

Comisión Nacional de Derechos Humanos. (2018). Los desafíos de la migración y los albergues como oasis. Encuesta Nacional de Personas Migrantes en Tránsito por México. México: Comisión Nacional de Derechos Humanos/Universidad Nacional Autónoma de México.

Flores, María Elena. (2012). Políticas públicas en México. Régimen político, finanzas y políticas sectoriales. México: Universidad Autónoma Metropolitana-Iztapalapa.

Gil Olmos, José. (2015). La 72, una casa para migrantes en medio del infierno criminal, Proceso, (2156), 25 de noviembre. Disponible en: http://www.proceso.com. $\mathrm{mx} / 421616 /$ la-72-una-casa-para-migrantes-en-medio-del-infierno-criminal

Google Maps. (2020). Mapa de la frontera México-Guatemala. Disponible en: https:// www.google.com.mx/maps/@17.2666869,-91.0087763,54610m/data=!3m1!1e3

Gutiérrez Albertos, Víctor Hugo. (2017). La 72 como espacio intercultural de emancipación y resistencia trans en la frontera sur de México. Península, XII (2), julio-diciembre, pp. 69-94. Disponible en: http://www.revistas.unam.mx/index.php/peninsula/ article/view/61048/53858

Hernández Mar, Raúl. (2018). Entrevista al Doctor Luis F. Aguilar Villanueva. An@lítica, 1. Disponible en: http://revista-csh.ler.uam.mx/index.php/rda/article/view/49

La 72. (s.f). La 72 Hogar-refugio para personas migrantes. Disponible en: https://la72.org/ nosotros/

Luna González, Erick. (2018). El voluntariado en las casas de migrantes: La experiencia como voluntario en La 72. Espacios Transnacionales. Revista LatinoamericanaEuropea de Pensamiento y Acción Social, 5 (10), enero-junio. Disponible en: http:// espaciostransnacionales.org/wp-content/uploads/2019/07/ET_10_ERI.pdf

Mauss, Marcel. (1971). Ensayo sobre los dones. Motivo y forma del camino en las sociedades primitivas, en Sociología y antropología, Madrid: Tecnos.

Ortner, Sherry. (1995). Resistance and the problem of ethnographic refusal. Comparative Studies in Society and History, 37, pp. 173-193.

Pérez Salazar, Juan Carlos. (2015). Así ocurrió la peor matanza de inmigrantes en México. BBC News, 21 agosto. Disponible en:

https://www.bbc.com/mundo/noticias/2014/08/140828_mexico_matanza_inmigrantes_ centroamericanos_aniversario_jcps 
Petrich, Blanche. (2014). El Viacrucis surgió por la violencia contra migrantes. La Jornada, viernes 25 de abril, p. 31. Disponible en: http://www.jornada.unam.mx/2014/04/25/ politica/009n1pol

Scott, James. (1985). Weapons of the Weak: Everyday Forms of Peasant Resistance, New Haven and London: Yale University Press.

Scott, James. (2000). Los dominados y el arte de la resistencia. México: ERA.

\section{Cómo citar este artículo:}

Castro Garcés Ana Paula y Pablo Castro Domingo. (2020). La 72, Hogar-refugio para personas migrantes: la sociedad civil organizada en la atención de la agenda de los transmigrantes en la frontera México-Guatemala. Revista Pueblos y fronteras digital. 15, pp. 1-33, doi: 10.22201/ cimsur.18704115e.2020.v15.502 